\title{
Diálogos à flor da pele... Nota sobre as saudações na Amazônia
}

\section{Philippe Erikson \\ (Université Paris-Ouest \\ Nanterre)}

\section{INTRODUÇÃO}

O tema das saudações, em particular quando estão ligadas a contextos cerimoniais, não é inteiramente novo para a área amazônica. Estamos certamente longe de contar, como acontece na África Ocidental, com teses inteiras dedicadas ao assunto ${ }^{2}$, mas ao menos existe uma importante monografia intitulada We/come of Tears (Wagley 1977), e dispomos ainda dos trabalhos pioneiros de Constant Tastevin (1909), Niels Fock (1963) e Peter Rivière (1971). Mais recentemente, a questão tem sido retomada, entre outros, por autores como Crépeau (1993), Gnerre (1987), Howard (1993), Lizot (1994), Schoepf (1998) e Viertler (1976).

Entretanto, é preciso observar que são essencialmente as formas de saudação extraordinárias que têm retido a atenção dos americanistas. Em outras palavras, sabemos muito mais sobre os sofisticados diálogos rituais praticados em encontros de caráter cerimonial que sobre as práticas cotidianas. Raras são as monografias que indicam, por exemplo, qual é a primeira coisa que se diz a seu vizinho após um período de separação relativamente curto. Esse tipo de informação se encontra algumas vezes desviada de uma narração ou de um texto didático ${ }^{3}$, mas raramente é objeto de maiores desenvolvimentos. Gostaria então de deter-me um pouco sobre a arte e a maneira de se saudar entre algumas etnias amazônicas, o que não me impedirá de sucumbir ao costume de dizer algumas palavras sobre as saudações extraordinárias que anteriormente se praticavam no seio de uma entre elas, os Chacobo da Amazônia boliviana.

Antes de fazer etnologia entre os Chacobo, tive a oportunidade de trabalhar com outra etnia da mesma família linguística: os Matis ${ }^{4}$. O contraste extremo entre esses dois grupos pano, no que diz respeito às suas formas de saudação, é, sem dúvida, uma das razões principais de meu interesse pelo assunto. De fato, como 
que respeitam certa etiqueta para saudarem-se e despedirem-se, os Matis não se saúdam por assim dizer. A hipótese que gostaria de propor aqui é que a maior codificação das fórmulas de saudação chacobo, em comparação àquelas dos Matis, não é sem relação com suas diferenças no plano da organização social e política. Uma história diferente, um sistema de saudação diferente.

Ao longo do caminho, tratar-se-á de mostrar que certo número de princípios que preside a disposição espacial e o deslocamento dos saudadores chacobo rege igualmente a organização geral de certos de seus rituais e certas de suas prestações de tipo econômico, em particular o trabalho do genro. Em suma, tratar-se-á de defender a ideia segundo a qual uma mesma "sintaxe", uma mesma "coreografia", em todo caso uma mesma "lógica", se encontraria em certas formas de saudar, em certas formas de beber, em certas formas de dançar e em certas formas de trabalhar, veiculando em cada ocasião uma mesma mensagem de ordem essencialmente política.

Por outro lado, gostaria de sugerir que, além das dimensões sociológicas e políticas frequentemente postas em cena pelos diálogos cerimoniais, as saudações amazônicas compreendem igualmente uma dimensão que se poderia qualificar como ontológica. As saudações amazônicas, mesmo as mais corriqueiras, parecem, com efeito, frequentemente destinadas a delimitar uma fronteira entre mortos e vivos, donde a tensão que as caracteriza e donde se explica também o título deste artigo.

\section{SAUDAÇÕES MATIS}

Entre os Matis, o protocolo que rege os encontros se reduz a sua mais simples expressão. Quando duas pessoas se cruzam, ou quando se visitam, contentam-se frequentemente de colocar uma questão puramente fática, ou factual. A alguém que vem molhado do igarapé, dir-se-á, por exemplo, "nesash mibi", "você tomou banho?" 5 . Se se encontra uma mulher que vem do roçado carregando tubérculos, perguntar-se-á "atsa berash mibi", "foi buscar mandioca?". A pergunta mais corrente, suficientemente estereotipada para dar o ar de ter-se formado uma quasefórmula de polidez, é: "autsi mibi pia", "o que você comeu?". Esse início permite ao interlocutor seguir a conversa sobre os temas conexos da ausência de carne e/ou das últimas proezas cinegéticas de uns e de outros. Entretanto, que essa pergunta seja mais retórica que pragmática emerge do fato de que se a faz mesmo quando restos da última refeição ainda estão espalhados no chão. Notemos, por outro lado, que essa maneira de saudar apresenta a particularidade de deixar a iniciativa de tomar a palavra ao visitante, o que é incomum no contexto sul-ameríndio.

Tampouco as palavras de acolhida que os Matis reservam aos estrangeiros, em particular aos brancos que chegam pela primeira vez, são carregadas de formalismo. As primeiras palavras que lhes são dirigidas se resumem frequentemente a um simples "autsine mibi", "como você chama?", ou mais literalmente: "o que é você?". Mesmo em encontros que saem da rotina, as saudações nunca são padronizadas. Um rapaz que conviveu bastante com os brancos (atuando como intérprete nas operações de "pacificação" dos Korubo) me disse certa vez que existia, em sua língua, um equivalente ao "bom dia" dos neobrasileiros: "isukuna?" ("você acordou?"). Entretanto, o fato 
de que foi preciso mais de quinze meses de campo para me dar conta de sua ocorrência é índice sério da sua raridade, se é que não se trata de um neologismo inventado durante uma dessas sessões de lexicologia comparada que ocupam as horas nas frentes de contato.

As fórmulas de separação matis são tão raras quanto lacônicas. Frequentemente contentam-se com um breve "erekavi", "vou para casa", ou "kwanek eobi", "estou de saída", expressões que podem recolocar (ou reforçar) pelo equivalente gestual, que consiste em colocar a mão aberta diante de seu nariz (palma da mão paralela à aresta nasal) e distanciá-la indicando a direção que se pretende seguir. O interlocutor responde geralmente "ai", "sim", ou "kwanta", "vá!". Destaquemos que o gesto daquele que se despede, mesmo que perfeitamente icônico, não alcança toda sua significação a não ser que se considere que o nariz, entre os Matis, é o orientador por excelência. Todo objeto animado ou inanimado é, em efeito, dotado de um deshan ("nariz"), orientado em direção da trajetória, espacial ou temporal, que ele deve seguir (Erikson 1989).

Exceto em certos rituais, a única ocasião que pode ocasionar uma forma de saudação nitidamente mais complexa é aquela de uma separação "conflituosa", ou seja, quando dois antagonistas decidem abandonar a aldeia, cada um por seu lado, para deixar o tempo cicatrizar suas diferenças. Ao invés de "saudação", talvez fosse mais adequado falar aqui de "diálogo de separação". O ritual, se se pode chamar assim, é tão simples como comovente, ao menos para um observador estrangeiro. Os dois antagonistas, em pé, cara a cara, a pouca distância um do outro, a cabeça ligeiramente inclinada, enumeram simultaneamente, com a voz baixa mas rapidamente, a lista - algumas vezes considerável - de agravos que imputam a seu adversário: "você não me deu carne", "você se mostrou preguiçoso em tal ou qual ocasião", "foi você quem roubou meus ovos de tracajá", "você se deita frequentemente demais com minha mulher", etc...

Cada um evita olhar seu antagonista e, sobretudo, cada um fala em seu próprio ritmo endiabrado, sem parecer prestar a menor atenção às palavras do outro e, de fato, em um tom apenas audível. Uma vez terminado esse simulacro de diálogo, cada um sai bruscamente para seu lado e ao menos um dos contendores pega suas coisas e parte para acampar na floresta alguns dias; ou mesmo algumas semanas, nos casos mais sérios. Na volta, não haverá mais perguntas da querela, ao menos até a próxima "crise"...

Se acaso exista, seria tentador incluir tais interações na categoria de "antidiálogos", no lugar daquela de "diálogos rituais". Sua encenação parece, de fato, menos destinada a sustentar a interação verbal que a parodiála, ou mesmo a negar sua possibilidade, ou, em todo caso, a sua pertinência real, como para melhor significar o propósito de não-receber que, no fim das contas, ela implica. Esta é, em efeito, uma forma de comunicação das mais minimalistas, uma vez que, sendo extremamente codificada e convencional, não visa mais que tornar manifesta a impossibilidade de se comunicar eficazmente. Ambos se falam, cara a cara, mas não se olham, não se escutam, ninguém faz qualquer esforço para ser audível. Em suma, simula-se dialogar para melhor ilustrar o impasse comunicativo em que, de fato, se encontram. Trata-se menos de formalizar uma separação que de oficializar o prelúdio a uma ruptura.

Isso posto, embora os interlocutores pareçam simular a comunicação para melhor indicar, de maneira claramente icônica, o impasse relacional em que se encontram, existe efetivamente diálogo na medida em que a 
enumeração das acusações é bastante direta e está longe de cair em ouvidos moucos. Ao contrário da situação yanomami descrita por Lizot (1994), na qual se exprime por perífrases para formular pedidos "polidos", trocase aqui informação "bruta" para justificar sem rodeios a impossibilidade de persistir com a relação. A despeito das aparências, cada um é perfeitamente consciente das asserções que o outro lhe dirige, isso para não falar da assistência...

Além disso, enquanto um antidiálogo - e talvez precisamente em virtude dos constrangimentos impostos por esse gênero um tanto especial -, o discurso de ruptura matis se apresenta igualmente como um tipo de "antidisputa". Com efeito, a obrigação de dialogar a minima, sem levantar nem os olhos nem o tom, faz com que ainda que aparente ser uma disputa (uma vez que se trocam verbalmente verdades cruéis), esse tipo de interação verbal não possa engendrar mais que uma violência muito limitada. Disputa-se, certamente, mas, em virtude das convenções dialógicas, deve-se fazer isso com voz e olhos baixos, os braços estendidos ao longo do corpo, sem gesticular ou gritar. Assim, os constrangimentos próprios do diálogo parecem refrear a violência potencial da querela (donde a ideia de "antidisputa") - da mesma maneira que a aspereza do contexto parecia dissipar qualquer veleidade de dialogar verdadeiramente -, transformando-a em autoescárnio (donde a ideia de "antidiálogo")... Em suma, o diálogo e a disputa se inibem, ou, ao menos, se temperam um ao outro.

Pode-se perguntar em que medida as práticas descritas acima constituem uma especificidade matis. Dean (1994:94) nota que quando se lamentam, zangadas, as mulheres uranina falam olhando o chão. Seja como for, o dito permanece: os Matis interpelam-se, trocam deliberadamente banalidades, balbuciam, mas não se pode dizer que existam saudações standards. Tal parece ser, por outro lado, o caso na maioria das sociedades amazônicas. Os Chacobo, ao contrário, têm fórmulas de saudação convencionais que utilizam escrupulosamente no cotidiano - o que, diga-se de passagem, desconcerta muito menos o etnólogo que as maneiras matis.

\section{SAUDAÇÕES CHACOBO}

Em tempos normais - ou seja, fora do contexto cerimonial -, os Chacobo contemporâneos se cumprimentam perguntando "bësoa mia?", "você está acordado/vivo/atento/alerta?". Pergunta à qual - a menos que se esteja dormindo, morto, distraído, mudo ou irritado - responde-se naturalmente com a afirmativa "bësoquëa", "estou acordado/vivo/atento/alerta".

O verbo bëso-, como sugere a tentativa de tradução proposta acima, é eminentemente polissêmico. Ele é empregado tanto no contexto da caça (quando se discute se o animal está já morto ou não) quanto em uma partida de vôlei (para encorajar os parceiros à vigilância) - isso para não dizer das traduções da Bíblia (sobre a ressurreição) e das conversações ao alvorecer (uma vez que bëso- significa também "acordar, levantar-se").

Seria, sem dúvida, perigoso tentar delimitar qual das acepções de bëso- enumeradas acima é aquela que domina seu emprego como fórmula de saudação ${ }^{6}$. Pode-se, no entanto, destacar que os velhos a empregam a 
qualquer hora do dia. Só os jovens tendem a restringir sua utilização à manhã, preferindo usar no período da tarde fórmulas prontas tais como "jënima ni mia [ri]" ("você está bem [você também]?") ou "mi qui shishoquia" ("eu vim te visitar"), às quais se responde geralmente "jënima xo ëa [ri]" ("eu vou bem [eu também]") ou "joquë mia" ("você veio"). Em resumo, poder-se-ia pensar que os jovens, influenciados pela oposição entre buenos dias e buenas tardes em espanhol, enfatizem a acepção "desperto/acordado" de bëso-, enquanto os velhos insistem mais sobre as acepções "ontológicas" do termo: a sensação de estar "alerta/ativo/vivo". Voltarei ao assunto adiante7.

A maneira típica de despedir-se entre os Chacobo consiste em dizer "catsiquia, fulano" ("vou-me agora, fulano"), repetindo a fórmula tantas vezes e com tantos nomes diferentes quanto sejam as pessoas presentes. Assim, no momento de deixar a casa de uma família composta, por exemplo, de Jërë, de sua mulher Jëma, e de seus filhos Kako, Tani e Baita, seria mal educado não dizer textualmente: "catsiquia Jërë, catsiquia Jëma, catsiquia Kako, catsiquia Tani, catsiquia Baita" (literalmente: saio agora esposa, saio agora Kako, saio agora Tani, saio agora Baita). Na ocasião de visitas intercomunitárias, a cerimônia pode demorar bastante tempo, uma vez que cada um que sai saúda todos do grupo que deixa. As pessoas saudadas geralmente respondem "jo" (ok), ou "cata" ("vá!")

Pude observar uma variante desta forma de saudação na saída de uma refeição coletiva servida aos convivas vindos realizar um trabalho de interesse geral, por ocasião da abertura de um futuro campo de futebol. No momento de deixar sua anfitriã (chamemos-na Jëma) e sair para ir ajudar seu marido a realizar a tarefa prevista, cada um, ao se levantar, diz "piqu[ë ë]a, Jëma", "eu comi, Jëma", e cada um recebeu a réplica "jo"("ok").

Anunciar "vou-me/parto" para despedir-se é uma prática relativamente bem distribuída na região Amazônica, que se encontra em praticamente toda a área pano. Existe mesmo um poema inteiramente consagrado à significação do termo kancaia, "vou-me/parto", em kaxarari (Barbosa, 1986)! Em contrapartida, a reiteração sistemática de todos os nomes das pessoas presentes é um fenômeno mais raro e a propósito do qual gostaria de arriscar a hipótese de que se trata talvez de uma discreta alusão ao tema da morte, que se imiscui frequentemente nas saudações amazônicas, como veremos adiante.

O nome, na área pano, indica uma posição na esfera dos vivos, e o dos defuntos não lhe deve mais pertencer (Erikson, 1993; 1996, ch.8). Segundo McCallum (1989: 108 ss), uma das funções atribuídas aos ritos funerários dos Caxinauá consistiria precisamente de separar o defunto de seu nome, para desvincular o nome de seu antigo portador. Um dos informantes chacobo de Balzano (1984), que lhe contou de seu encontro com o fantasma de um certo Mariano, teria dito: "Mariano's own body would have recognized us, but his yushini does not recognize us. His yushini has forgotten our names". Encontra-se a mesma ideia entre os Amahuaca, entre os quais "yoshi have no names" (Huxley \& Capa 1964:110), do mesmo modo que entre os Marubo, que pensam que os yoshi só se interpelam através de termos de parentesco, jamais utilizando os nomes próprios (Montagner Melatti, 1985:168). Ter um nome, em toda a área pano, é estar vivo, e é às vezes explicitamente percebido como uma garantia de longevidade, como entre os Katukina (Lima, 1997).

Enunciar o nome próprio de alguém aparece assim como um meio de reafirmar a sua existência. É, sem dúvida, por isso que, quando um Chacobo, que não se chamava de outro modo a não ser por seu apelido de 
Shamo, ficou gravemente doente e se encontrava entre a vida e a morte, todo mundo se pôs de repente a chamálo com seu verdadeiro nome: Cuya. Tais fatos levam a pensar que dizer o nome quando se saúda pode ser um meio tão discreto quanto inegável de desejar vida longa àquele de que se separa, ou ao menos de reafirmar sua qualidade de vivo.

Pareceria, então, que tanto a forma de saudação (bëso-) quanto a maneira de despedir-se teriam, entre os Chacobo, uma dimensão que se poderia qualificar de ontológica, sobre a qual voltarei a falar na conclusão. Ao contrário, as saudações reservadas aos "grandes homens" do passado operariam a partir de outra lógica, de essência nitidamente mais política.

\section{A ARTE DE SAUDAR UM GRANDE HOMEM CHACOBO}

Diferentemente dos Matis, herdeiros de sociedades amazônicas "clássicas" (expressão que não quer dizer nada, mas que todo mundo compreende), os Chacobo dão a impressão de ter conhecido, em um passado ainda bastante recente, uma forma de organização política relativamente complexa e provavelmente não igualitária. Longe do modelo clastriano do líder sem poder, os antigos chefes chacobo, chamados chama chamaria, dispunham de certo número de privilégios e de poderes bastante destacados: portavam ornamentos corporais distintivos, e as pessoas, quaisquer que fossem suas idades ou seus laços de parentesco, dirigiam-se a eles chamando-os chaita, "avô". Apenas alguns notáveis (ou alguns descarados) podiam se permitir encurtar a distância genealógica chamando-os papa, "pai" 9 .

Diz-se que esses chefes eram constantemente acompanhados por seis guarda-costas, três de cada lado, que faziam eventualmente o papel de carrascos, dado que os chama chamaria dispunham aparentemente do direito de vida e de morte sobre todo o pessoal da sua aldeia, além de que faziam e desfaziam casamentos. Esses personagens eram, além disso, assistidos por dois suplentes (chitiminati), chamados "mão esquerda" e "mão direita", dos quais ao menos um devia permanecer na aldeia a fim de representar a autoridade no caso de ausência momentânea do chama chamaria. Uma de suas funções era vigiar para que ninguém tentasse se sentar em seu trono (quënánë) ${ }^{10}$, colocado no meio da casa dos homens, onde ele encarnava a permanência centralizadora da autoridade existente.

Metade da caça era-Ihe devida: a parte trazida pela esposa do caçador ia à sua família, enquanto que a parte trazida pelo homem ia ao chefe. Ainda hoje, diz-se que o urubu-rei (poico roa) é o chama chamaria dos pássaros predadores, visto que ele os manda caçar em seu lugar. Além disso, os chefes dispunham de enormes roçados comunitários, cuja imensidão tinha impressionado fortemente os viajantes de séculos precedentes (Armentia 1976[1882]). Essas superfícies requeriam uma mão-de-obra tanto mais importante que se acrescentava terra a cada ano para que elas durassem mais tempo. Os chama chamaria eram sempre dispensados dos trabalhos menores/ indignos. Mais uma vez encarnando, ao mesmo tempo, o centralismo e a imobilidade federativos, sua única tarefa consistia de manter os fogos necessários para re-instalação dos machados de pedra dos trabalhadores. 
Os chefes dormiam no centro da casa dos homens, enquanto os outros dispunham suas redes na periferia. Além disso, diferentemente das pessoas comuns, eles gozavam da prerrogativa de ser enterrados em urnas. Todas essas características fazem evidentemente pensar nas sociedades da província vizinha de Mojos, célebres por seus imponentes campos elevados (Denevan, 1980) e onde Eder (1985:84-85), a propósito dos Baurés, fala de uma classe de chefes hereditários (e de 'aristocratas'), dispensados de toda atividade física, acompanhados de dois assistentes (mão esquerda e mão direita?) e investidos de poderes consideráveis...

Em tal contexto, não surpreende que tenha existido, entre os antigos Chacobo, ritos de saudação bastante elaborados. Se se acredita nas descrições dos antigos que ouviram falar dessas coisas, aproximar-se de um grande-homem tradicional do tempo de seu esplendor exigia o respeito de uma verdadeira etiqueta. Era preciso carregar as flechas com as pontas viradas para baixo para manifestar suas intenções pacíficas e, sobretudo, parar-se a intervalos regulares para se inclinar à sua frente em sinal de respeito. $O$ protocolo de aproximação era aparentemente simplificado para os convidados importantes: o número de etapas (e, então, de reverências) era inversamente proporcional ao prestígio reconhecido ao visitante. Além disso, quanto mais o visitante tivesse um status elevado mais the era permitido aproximar-se do chefe. Ainda que arriscando um incidente diplomático, um notável de nível equivalente ao daquele que o recebia podia reduzir as formalidades ao mínimo e chegar muito perto de seu anfitrião.

As palavras trocadas durante esse ritual não parecem apresentar nada de excepcional. Aparentemente não existia nenhuma fórmula verbal de saudação que marcasse especificamente a subordinação hierárquica do visitante. Contentavam-se de dizer algo completamente comum, como "jënima ni mia ri?", "você também está com boa a saúde", ou "mi qui shishoquia", "eu vim te visitar". Entretanto, a linguagem das posturas era tudo o que há de mais explícito: as saudações ao chefe traduziam as relações hierárquicas.

Esse ponto merece que paremos aqui. Vários observadores, tais como Esther Goody (1974) ou Raymond Firth (1970), têm destacado a diferença entre, por um lado, as saudações simétricas entre iguais, como o aperto de mão no Ocidente ou a fricção de narizes dos Tikopia, e, por outro, as saudações assimétricas, que implicam em uma atitude de submissão e representam frequentemente um ato de fidelidade. A maioria das saudações amazônicas é, até onde sei, de tipo simétrico, mais próxima do abraço que da reverência. A saudação dos antigos Remo constitui um exemplo particularmente espetacular, visto que consistia de um pequeno jogo de balanço no curso do qual o anfitrião e seu visitante, cara a cara, se apertavam respectivamente pelas nádegas e levantavam-se um do outro do solo alternadamente:

"greetings between friends took the form of standing chest to chest, grabbing each other by the buttocks and alternately lifting one another several times" (Tessmann citado em Whiton et al.:115).

Igualmente simétricas são, entre outros exemplos possíveis, a palpação ventral recíproca dos Bari (Galvis 1995: 86), ou ainda o mapatsanati dos Kaxinawá, uma saudação de luto que consiste numa fricção mútua de 
cabeças, às vezes acompanhada da cobertura recíproca dos corpos dos saudadores-chorões com o muco que escorre de seus narizes (Tastevin 1925; Kensinger 1995:228).

Os exemplos de saudações assimétricas e sinais de respeito são, em contrapartida, nitidamente mais raros na área amazônica. Encontram-se certamente exemplos espetaculares para as sociedades estratificadas da MesoAmérica, da Flórida e dos Andes. ${ }^{11}$ Entretanto, para as baixas-terras, até agora não encontrei mais que uma única alusão a fenômenos comparáveis, relativo aos Irurí do Médio Amazonas que:

"também parecem ter tido uma cultura bastante desenvolvida,caracterizada por uma organização social baseada em forte hierarquia política, elaborada etiqueta, 'vassalagem', além de uma cultura material aprimorada" (Menéndez 1984/5: 273; grifos do autor) ${ }^{12}$.

Não há porque duvidar que as sociedades dos llanos de Mojos, que avizinhavam os Chacobo, tenham conhecido uma forma de organização política de uma complexidade comparável àquela das sociedades de que fala Menéndez. A dimensão hierárquica notória manifesta pelas saudações respeitosas dirigidas aos chama chamaria se explica, sem dúvida, assim.

\section{SAUDAR E BEBER}

Para deixar a etnohistória e voltar aos Chacobo contemporâneos, destaquemos que eles não falam de suas antigas "saudações distintas" sem evocar as festas de cerveja tradicional. As maneiras de beber, a maneira de dançar e a antiga maneira de saudar os chefes, de fato, têm em comum que o objetivo da manobra consiste, nos três casos, em avançar o máximo possível de um centro altamente valorizado, a despeito dos diversos obstáculos de ordem quase-protocolar interpostos entre esse ponto de convergência e o visitante, o dançarino ou o bebedor que procura aproximar-se.

Isso é muito claro no caso das saudações, onde se aproxima do chefe instalado no meio da casa dos homens por arrancos - para não dizer que por saltos de pulga - entrecortados de reverências cerimoniais. Isso é igualmente claro no contexto das festas, onde o objetivo a atingir torna-se o recipiente de cerveja colocado no meio da casa dos homens, no mesmo lugar que era outrora reservado ao chama chamaria. Os convidados não podem alcançar esse lugar sem antes ter "prestado honras" aos recipientes intermediários colocados à sua disposição entre o ponto de chegada (o porto ou o caminho pelo qual chegam) e o objetivo visado (o recipiente central).

Trata-se ainda de se aproximar por etapas do centro positivamente conotado, marcando as paradas para cumprir seus deveres de hóspede: no caso, terminar a cerveja que lhes é ostensivamente servida a fim de poder se atracar a outro recipiente, colocado um pouco mais perto do centro. Nos dois casos, quanto mais prestigioso é o visitante, mais rapidamente acede ao centro. Um homem capaz de mobilizar um séquito imponente não terá nenhum problema para terminar a cerveja que lhe é oferecida e chegar facilmente à etapa seguinte. Ao contrário, um 
hóspede de menor prestígio corre o sério risco de sofrer a humilhação de ficar retido no porto, afastado do coração da festa por sua incapacidade de dar conta das quantidades impressionantes de cerveja que lhe são reservadas ${ }^{13}$.

Durante as festas, a disposição dos dançarinos em torno do pote de cerveja e as manobras às quais as orquestras de flautas de pã se entregavam para se aproximar relevam de uma dinâmica igualmente centrípeta. Os dançarinos estavam dispostos em círculos concêntricos hierarquizados pela distância maior ou menor que os separava do pote de cerveja central. O primeiro anel era reservado ao xamã (yobëca) e às suas duas assistentes, que dançavam bastante perto do coração da festa, ao ritmo de um tambor de cerâmica com membrana de goma/ seringa. Imediatamente atrás, evoluíam as orquestras compostas de homens adultos, dispostos em ambos os lados de seu líder e cada um com um instrumento composto de cinco tubos de taboca. Um pouco mais atrás vinham os adolescentes, que dançavam também repartidos em várias filas. Enfim, relegados à periferia, no anel mais distante, encontravam-se as mulheres (salvo as duas que acompanhavam o xamã andrógino) e todas as crianças. Entretanto, aqui ainda, os agenciamentos não eram puramente estáticos, uma vez que no interior do estrato que Ihes era reservado, os chefes de orquestra, cada um acompanhado de seus assistentes ("mão direita" e "mão esquerda"), rivalizavam para se aproximar do centro dançando para frente e para trás. Em meio a uma precipitação generalizada, ritmada pelos desafios musicais em que se lançavam como se fossem pequenas chefaturas lutando pelo poder, cada uma das orquestras se esforçava para chegar o mais perto possível do centro que as outras.

Notemos, de passagem, que um esquema muito similar se encontra ao menos em uma das provas que um sogro fazia seu futuro genro passar antes de lhe ceder sua filha. Para provar seu valor, o postulante deveria preparar sozinho um roçado de forma evidentemente circular e bem provido de um centro eminente: neste caso, uma castanheira da Amazônia (Bertholletia excelsa), uma das árvores mais imponentes que se pode encontrar na região ${ }^{14}$. Ora, como se terá imaginado, a árvore deveria ser derrubada por último, uma vez ultrapassados - ou antes, desbastados - os obstáculos periféricos.

Assim parece realmente ter existido, entre os Chacobo, uma lógica do tipo concêntrica que presidia a disposição tanto do trono do chefe quanto da árvore do genro, e que preside sempre aquela do pote de cerveja. Antes que concêntrica, talvez fosse o caso de qualificar esse arranjo de "nuclear": tanto mais pelo fato de que ele se caracteriza pela conjunção de um núcleo central e de elementos gravitando em sua periferia do que por um simples encaixe de anéis hierárquicos de maneira estática.

Qualquer que seja a admirável recorrência desse esboço "nuclear", retenhamos simplesmente que as maneiras de saudar e as maneiras de beber apresentam, entre os Chacobo, pontos de convergência notáveis. De resto, não convém surpreender-se, estando dado que a partilha de cerveja de mandioca pode ser considerada - entre os Chacobo como em muitas outras partes da Amazônia - como o aditivo principal de toda vida social. Saciar a sede dos visitantes, mesmo que fora de qualquer contexto cerimonial, é sempre o primeiro gesto que se faz para lhes recepcionar. Alguém que chega de improviso numa casa desprovida de cerveja vê geralmente o dono se desfazer em desculpas, embaraçado pelo fato de não poder dignamente receber seus hóspedes. Dar de beber e saudar vão, por conseguinte, juntos, assim como ter bebido e pedir licença para sair coincidem muito 
geralmente: as regras de boas maneiras chacobo exigem que se deixe a casa de seu anfitrião logo que se tenha esgotado suas reservas de cerveja. ${ }^{15}$

Podemos, por outro lado, destacar que a maneira como a cerveja é servida entre os Chacobo contemporâneos segue um esquema que se acomoda perfeitamente a uma lógica de centralização do poder. Por contraste com o que parece ser a modalidade de serviço mais bem distribuída na Amazônia, o dono da cerveja delega o cuidado de servir a bebida a um indivíduo particular, que, após ter se servido, se encarrega de oferecer uma calabaça a cada um dos bebedores; as quantidades e a ordem sendo deixadas à sua apreciação. Geralmente, o encarregado pelo serviço começa a servir os bebedores sentados em torno do recipiente de cerveja e os serve por turnos, seguindo a ordem na qual estão instalados. Há, assim, um único responsável pela distribuição, ao qual tem sido delegado o poder de saciar todo mundo a partir de um ponto central. Notem que se trata de um papel considerado mais honorífico que servil, uma vez que, como se diz, exige certo tato a fim de não ofender ninguém durante a distribuição, dando-Ihe em demasia ou demasiadamente pouco...

Nas sociedades de tradição mais igualitária, que são sem dúvida a maioria na área amazônica, o que se poderia chamar de "reciprocidade etílica" é bem mais imediata. Cada um oferece uma calabaça cheia a seu vizinho à esquerda (por exemplo), que lha devolve (cheia) quando ela volta em sentido contrário, circulando desta vez da esquerda para a direita. Há, então, duas maneiras de beber bem diferentes: seja "em cascata", como entre os Chacobo ou nos Andes, onde um ápice rega a base, seja "em rede", como entre os Curripaco ou os Wayana, onde reina o princípio do arroseur-arrosé, "regador-regado" 16.

Destaquemos, finalmente, para encerrar essa seção sobre bebidas e saudações que, quando alguém retorna de uma longa viagem e/ou acaba de escapar da morte, se pratica um pequeno ritual que evocará sem dúvida muitas lembranças aos andinistas. Trata-se, em efeito, de um tipo de libações que não deixa de lembrar a chall'a, uma vez que consiste em repartir algumas gotas de cerveja na frente dos pés de cada um dos convidados reunidos para celebrar o retorno do "viajante" 17 . Aqui ainda bebidas e saudações vão juntas, a tal ponto que ambas se confundem em um único e mesmo gesto: o derramamento da cerveja.

O fato de que existe um vínculo entre bebida e longevidade ressalta bastante claramente do pequeno ritual evocado acima, que supostamente prolonga a vida do oficiante. O mesmo vale para os rituais de bebida "ordinários", que deviam prolongar-se toda a noite se os dançarinos quisessem viver muito tempo, mas deviam começá-los ao raiar do dia; sem dúvida para se diferenciar dos espíritos, que bebem à noite. Beber resulta assim, no fim das contas, como uma maneira de reafirmar seu pertencimento ao universo dos vivos, o que constitui um outro ponto em comum com as saudações.

\section{DIALOGAR ENTRE VIVOS}

Recordemos que da mesma maneira que as festas de bebida, as saudações "ordinárias/corriqueiras" dos Chacobo 
interlocutores. Esta propensão que têm as saudações de desempenhar o papel de reafirmadores existenciais não tem nada de especificamente chacobo, nem mesmo de especificamente amazônico. Um pequeno panorama comparativo mostra que não há nada de surpreendente nisso. A ideia de que toda separação comporta o risco de tornar-se definitiva é bastante banal. Isso é demonstrado pelas torções que muitas vezes têm nosso próprio "adeus", que frisam frequentemente a benção e fazem alusão, mais ou menos diretamente, ao além. De uma maneira similar, entre os Guajiro:

“na véspera de uma longa ausência, se lhes diz "Vou-me", segundo a discreta formula indígena, todos, dos mais jovens aos mais velhos, respondem: 'Eu estarei morto na sua volta'" (Perrin, 1992:30).

E a propósito das despedidas que lhe reservaram os antigos Pacaguaras, parentes próximos dos Chacobo, Heath (1883:331-2) escreveu :

"as we cast off to continue our advance, the Pacavaras, men and women, stood on the bank and murmured 'death, death'.

Isso posto, o tema da morte, tão frequente nos ritos de saudação de todo o mundo, parece particularmente saliente na área amazônica; e ali distinguir-se-ia, um tanto paradoxalmente, por apresentar-se mais claramente nas ocasiões de reencontros que nas separações ${ }^{18}$. As saudações parecem tanto mais elaboradas se uma morte interveio desde o último encontro. Elas se complexificam à medida que a morte vem se insinuar no quadro, como o atesta a prática pan-amazônica (ou quase) da saudação lacrimosa - ocorre mesmo de os indígenas dirigirem-se a seu visitante como se ele estivesse entre a vida e a morte. Galvão (1996:307), por exemplo, a respeito da "saudação lacrimosa" dos Kamayurá, escreveu em 1950:

“Quando chega um companheiro de uma viagem, saúdam-no com pranto. Diz Leonardo que, no discurso chorado que se segue, as palavras são dirigidas ao indivíduo que morreu, cuja lembrança é associada ao que retorna".

É tentador reaproximar isso do fato de que por ocasião de bom número de rituais de máscaras amazônicas, são precisamente os visitantes que encarnam os mortos de seus anfitriões. Seja como for, retenhamos que as sociedades amazônicas prestam mais atenção aos protocolos que organizam os reencontros que àqueles que prenunciam a separação. A aparição (muito formalizada) prima aqui sobre o desaparecimento (minimizado) e se as partidas são frequentemente marcadas pela discrição, os encontros, em contrapartida, estão longe de ser tomados levemente.

A título de hipótese de trabalho, poder-se-ia sugerir que ênfase similar sobre o encontro em detrimento da separação ressalta da oposição que as sociedades amazônicas estabelecessem muito geralmente entre o espaço inofensivo da aldeia e o universo perigoso da floresta profunda, percebido como o domínio de espíritos potencialmente maléficos. No retorno da floresta, corre-se sempre o risco, para falar brevemente, de trazer as 
emanações dos espíritos. Sem dúvida é por isso que o banho no igarapé, tomado escrupulosamente antes de entrar na aldeia, parece sobressair da vulgata amazônica. Além disso, os Ticuna o interpretam explicitamente como uma medida destinada a se descontaminar de um eventual contato com os espíritos dos vegetais silvestres (J-P. Goulard, 1998).

Entre os Matis, mesmo quando se volta para sua própria casa após uma curta escapada silvestre à procura dos produtos os mais inofensivos, é de bom tom fazer uma parada antes de penetrar no espaço da aldeia, como se tratasse de retirar-se numa espécie de câmara de descompressão simbólica a fim de diminuir os riscos que faria incorrer (a si mesmo e, sobretudo, aos outros) uma transição muito brusca entre os universos contrastados (Erikson, 1988). O simples contato visual com um homem que volta da caça é considerado como altamente arriscado.

A pausa que sistematicamente os Matis fazem na borda da aldeia quando voltam de um deslocamento à floresta (mas não ao roçado) pode então ser considerada como parte integrante de um protocolo de interação, e talvez a extrema discrição que caracteriza suas maneiras de se saudarem não seja sem relação com ela. Veremos, contudo, que no que diz respeito às relações não mais intra- mas intercomunitárias, o fato de chegar vindo da floresta induziria mais a uma complexificação que a uma simplificação dos protocolos de acolhida dos visitantes - complexidade que, de resto, não é incompatível com uma fase de discrição obrigatória, necessária para se descontaminar previamente.

Por razões evidentes, os visitantes chegam quase sistematicamente após terem transitado pela floresta e, em particular quando se apresentam mascarados, acontece mesmo deles encarnarem espíritos silvestres. Em todo caso, as aparências podem ser enganadoras, é sem dúvida prudente assegurar-se da identidade real de seus visitantes, donde a importância dos rituais de boas-vindas e o caráter solene que frequentemente os revestem. Ehrenreich (citado em Kroemer, 1985:113), após ter descrito uma categoria de espíritos silvestres cuja aparição na aldeia era particularmente temida pelos Apurinã, escreveu que: “desta idéia [...] deriva a curiosa cerimônia de saudação, com que se recebiam indivíduos de aldeias estranhas, mesmo se estes fossem convidados para uma visita amistosa".

Segue uma descrição ${ }^{19}$ de um simulacro de ataque da parte dos visitantes, rico em vociferações e em ameaças que não deixam de evocar o começo das festas yanomami - tais como foram filmadas por Tim Asch, por exemplo - ou ainda certas práticas de "agressão retida" que parecem ter lugar de saudação entre os Yaminahua (Alvarez Lobo, 1961:17):

“[Camacho] pronunciaba un discurso en alta voz y muy de prisa, durante el cual tensaba el arco y lo aflojaba, corría al monte y al barranco en la misma posición, apuntaba al sol y nos apuntaba a nosotros. [...] Veíamos [a Elías] nuestro intérprete principal [...] intentando hablar con él, pero Camacho no le hacía caso y seguía hablando, saltando, corriendo, y apuntándonos con el arma. Eran las cinco y la sesión ya se extendía por dos horas [...] A esas horas estábamos sin saber si se trataba de recibimiento o de repulsa, pero era hora de conocerlo. [...Le] pregunté:'¿Qué dice?'. Elías, sonriente, me contestó: 'Esta muy contento porque hemos venido a visitarle".

Para voltar aos Apurinã, destaquemos o interesse das glosas indígenas evocadas por Kroemer para dar conta 
tivessem intenções hostis, viriam cumpri-las em silêncio. Tratar-se-ia antes de se separar dos espíritos da floresta. Nos dias de hoje, o componente guerreiro do ritual parece ter caído em desuso, mas as novidades são sempre dadas em voz alta, quase gritando, sendo a audibilidade percebida como uma característica da própria humanidade, por oposição aos espíritos silvestres. Saudar alto e forte contribui para anunciar sua humanidade.

Carid Naveira (1999: 114, n. 130) escreveu: “[os Yawanawa] me contaram também que antigamente existia uma forma de saudação que consistia na recepção do chefe que esfregava sua bunda na canela do visitante depois de ter defecado". Saudação estranha enquanto scatologique, mas inteligível enquanto eschatologique ${ }^{20}$, sabendo que para esse grupo étnico, segundo Conrad Feather (2010), a presença (ou ausência) de excrementos é um dos principais pontos de partida entre humanos e espíritos:

"A Nahua myth, poiyawediwo (they went with their poo) tells of a man who died and his relatives were so distraught that they followed him. The Weroyoshinahua (the weroyoshi people) in the land of the dead were disgusted, 'ech, they have come here with all their shit' they complained and even the weroyoshinahua's hammocks and benches deftly moved away when the people tried to sit down".

A sombra dos mortos e dos espíritos paira sobre os reencontros, seja porque uma morte ocorreu após o último encontro, seja simplesmente porque ao menos um dos saudadores chega geralmente da floresta, ou acaba de emergir do universo inquietante do sono (cf. o "bësoa" chacobo e os exemplos assinalados na nota 3). Saudar permite, assim, tirar uma dúvida sobre seu estatuto ontológico, a se reinserir na esfera do social e, de alguma maneira, a se desembaraçar do que pode ser um obstáculo a uma relação serena entre vivos.

Urban (1986) sugere que os diálogos cerimoniais sul-americanos aparecem essencialmente em contextos potencialmente conflituosos, a fim de reforçar a coesão social. Sem contestar completamente esta hipótese ligeiramente funcionalista, nem substituir uma explicação psico-simbólica por uma interpretação de ordem sociológica, parece-me importante evocar, a guisa de conclusão, a dimensão existencial subjacente às relações de interação entre hóspedes e visitantes amazônicos. Saudar consiste também em reduzir uma distância - seja temporal seja espacial - entre vivos, a levantar uma hipoteca sobre a ameaça que constitui a natureza falaciosa das aparências.

Tradução : Edilene Coffaci de Lima

Revisão: Eliane Camargo

Philippe Erikson é professor de Antropologia na Université Paris-Ouest Nanterre, onde se doutorou em 1990. É membro do Laboratório de Etnologia e Sociologia Comparativa, a partir do qual integra a Equipe de Pesquisa em Etnologia Amazônica. 


\section{NOTAS}

1 Redigido por ocasião do $49^{\circ}$ Congresso Internacional dos Americanistas realizado em Quito, em 1997, o texto que se segue foi publicado em francês nas atas do colóquio, onde ele tinha sido primeiramente apresentado (Becquelin \& Erikson, 2000). Visava essencialmente chamar a atenção dos pesquisadores sobre um tema pouco explorado: aquele das saudações "corriqueiras" na Amazônia, e abrir espaço apresentando alguns dados etnográficos sobre os Matis e os Chacobo. A análise comparativa das formas de saudações nessas duas etnias de língua pano permitia formular algumas hipóteses gerais sobre a maneira como os sistemas políticos, os códigos que regem as relações interpessoais e as ontologias se articulam nas baixas terras da América do Sul. Passados quase 15 anos, nosso conhecimento desses temas permanece bastante lacunar, a despeito dois estudos recentes que, em diálogo com o presente artigo, aumentam nosso corpus e parecem reforçar suas conclusões (Surrallès, 2003 e Passes, 2004). Apesar de relativamente antigo, espero que se justifique a republicação deste texto - com pequenos acréscimos - em uma versão em português, permitindo aumentar um pouco seu público leitor. Agradeço a Edilene Coffaci de Lima, que fez a gentileza de traduzi-lo, com a amigável cumplicidade de Eduardo Barra (para o título) e de Eliane Camargo; com grande prazer, saúdo-os de passagem.

2 Da vasta literatura extra-americanista consagrada às saudações, mencionamos Amenyedzi (1984), Wierzbicka (1995), Schottman (1995), Schiffrin (1974), Naden (1980), Labatut (1989), Collett (1983), Duranti (1992), Hall \& Hall (1983).

3 Alguns exemplos: Perrin (1992:49), a propósito dos Goajiro : “'Que teus sonhos sejam bons', 'veremos amanhã se você teve bons sonhos' são as maneiras de se dizer boa noite. 'Como foi teu sonho é o bom dia matinal'"; McCallum (1996: 361), a respeito dos Cashinahua: "[A] common form of greeting in the morning is: 'Did you dream and what?'"; Alvarez Lobo (1961:18), sobre os Amahuaca, evoca: "el modo frío con que ordinariamente se saludan [...]: '¿Has venido ?', al cual el visitante responde: 'Aja".

As obras didáticas, do tipo "Lecciones para el aprendizaje del idioma...", constituem uma outra fonte de informação interessante. Eakin (1991) ensina-nos, por exemplo, desde a primeira lição que entre os Yaminawa "mã min oimen, você veio? se usa como forma de dar 'bom dia'". Faust (1973) e Kneeland (1979) ensinam a mesma coisa sobre os Shipibo e os Matsés, respectivamente. E. Camargo (com. pessoal) utiliza como exemplos as duas formas seguintes de saudação: "dais, mi-n ma hu-ai","oi genro, você está chegando" e "ïwa-n ïn ma hu-ai", "oi mamãe, eu estou chegando", que é a mais original, visto que ela deixa a iniciativa àquele que chega.

4 Os Matis são uma etnia da Amazônia brasileira de aproximadamente duzentas pessoas que têm pouco contato com a sociedade regional, enquanto os Chacobo são cinco vezes mais numerosos e frequentam assiduamente os brancos há mais de um século. Desde 1985 pude passar 37 meses entre esses dois grupos graças aos apoios financeiros da DGRST, da Fundação Fyssen, do IFEA e do Laboratório de Etnologia e Sociologia Comparativa de Nanterre.

5 Quando escrevi este texto, a língua matis ainda não havia suscitado o interesse de um(a) linguista profissional, de forma que não pude propor mais que transcrições fonéticas aproximativas, livremente inspiradas do API. As citações em língua chacobo seguem a grafia introduzida pelos missionários do SIL e que, malgrado o fato de que seja calcada sobre o espanhol ( $j=h$; qu $=k$, etc), tem ao menos o mérito de existir.

6 Lembremos que um termo comparável se encontra entre os Guajiro (arawak), visto que, segundo Perrin (1992:34), kata'ouwaa significa tanto 'estar acordado' quanto 'estar vivo'. Esse tipo de polissemia é provavelmente muito espalhado na área amazônica, encontramo-la igualmente, entre outros, entre os Jivaro (Ph. Descola, com. pessoal).

7 A influência da sociedade nacional se faz igualmente sentir no sucesso certamente relativo, mas sem dúvida crescente, do aperto de mão, mesmo entre os Chacobo, ao menos no contexto urbano. Estamos longe da situação, relatada por Barbara Keifenheim (com. pessoal) para os Cashinahua dos anos 70, entre os quais os velhos explicam aos jovens que para saudar um branco era preciso Ihe triturar a mão, exclamando: "paciência, paciência"!

Notemos igualmente o sucesso muito relativo da fórmula de saudação introduzida pelos missionários para falar ao rádio: "jëni ca bari mi jayano", tradução literal de "que tenham um bom dia". A maior parte dos Chacobo termina suas ligações como eles terminam um discurso em praça pública, dizendo "yama noho chani"', literalmente "não tenho mais palavras", às quais se responde frequentemente "cata" ("vá"). 
8 Catahuë, com uma duplicação do imperativo (ca-: partir; -ta: imperativo polido; huë: imperativo estrito), ouve-se algumas vezes, mas dá a impressão de constranger os informantes quando utilizado a título experimental pelo etnólogo...

9 O termo se emprega sempre para se dirigir aos missionários suíços (papa Felipe e cai Alicia, "o pai Philippe e a mãe Alice") ou aos etnólogos franceses (papa Felipe e cai Helena, “o [outro] pai Philippe e a mãe Hélène).

10 Esses objetos, cujas belíssimas ilustrações podem ser encontradas na obra de Nordenskiöld (1924), apresentam a particularidade de ser compostos e montados com pregos de madeira.

11 Para os Andes, cf. Métraux (1962: 73-74). Para a Flórida, cf. Goggin \& Sturtevant (1964: 192): "“[The headchief] was greeted in a special way: the 'vassal' knelt and raised his hands palms up, and the chief placed his hands on top of them" (citação de Barrientos, 1902[1568]:88). Para a Meso-América, pode-se reporter às passagens edificantes de Bernal Díaz del Castillo (1980[1590]): “Des manières et de la personne de Montezuma, et comme quoi c'était un grand seigneur".

12 Menéndez apoi pers.) observa a mesma etiqueta entre os Wayana.

13 Mitrani (1978) descreve, entre os Yaruro da Venezula, rituais durante os quais as preliminares de aproximação faziam igualmente parte integral da cerimônia.

14 Estando a extensão do território chacobo hoje consideravelmente reduzida, a derrubada de castanheiras sendo proibida por lei e os frutos dessa árvore uma fonte de rendimentos importante, os genros devem, a partir de então, encontrar outros meios de exibir seu valor.

15 Eliane Camargo (com. pers.) observa a mesma etiqueta entre os Wayana.

16 Sobre as maneiras de beber "em rede", pode-se ler as excelentes descrições de Schoepf (1979) para os Wayana, e de Journet (1995) para os Curripaco. Sobre a maneira de beber "em cascata" nos Andes, pode-se consultar Martinez (1992), assim como a coletânea de artigos publicada pelo falecido Thierry Saignes (1993).

17 Como sempre acontece quando se compara os rituais andinos com suas aparentes contrapartes amazônicas, a referência ao divino, essencial nas altas terras, desaparece totalmente nas baixas terras. As referências cosmogônicas dão lugar a considerações relativas ao bem estar pessoal. As libações chacobo não visam atuar sobre a ordem do mundo pela divindade interposta, mas simplesmente assegurar a longevidade do oficiante.

18 Salvo considerar os ritos de luto como maneiras de saudar o morto por ocasião de sua partida. Os cantos de luto matis, que duram muito tempo e se caracterizam por um decrescendo muito gradual, sugerem de maneira bastante concreta e comovente o distanciamento progressivo do defunto.

19 Kroemer (1985:113-114) escreve: "Finalmente, as duas facções se encontravam face a face, ameaçadoras, as armas prontas para disparar. Seguia se um silêncio prolongado e soturno. O porta-voz dos visitantes apresentava propostas de paz e dava-se a conhecer como amigo. Afinal, depois de meia hora de discussão, entravam em acordo. Depunham as armas, e aos estranhos, que eram convidados a sentar-se, ofereciam-se os tubinhos de rapé da paz. Cada um tomava uma boa pitada. Enquanto isso, o porta-voz dos visitantes se aproximava do chefe da casa, ajoelhando-se a seus pés, e pondo-se a relatar, em frases entrecortadas e com o rosto virado para o chão, todos os acontecimentos que, em sua aldeia, se verificaram nos últimos tempos. Com voz fanhosa e na mesma tonalidade, o chefe da casa passava a responder-lhe, narrando ao estranho, igualmente de joelhos, as novidades de sua aldeia. [...] Se, entre os visitantes, também havia mulheres, originava-se igualmente entre as facções femininas uma animada discussão, mas de caráter cômico. Sentadas umas em frente das outras, com grande gritaria, batiam em todas as partes do corpo que podiam ser atingidas, submetendo a uma crítica depreciativa os encantos físicos das parceiras, que, em seguida, Ihes respondiam da mesma forma".

20 Preservou-se aqui o trocadilho francês, no qual o autor diferencia entre scatologie e eschatologie, o primeiro sentido vinculandose ao tema dos excrementos e o segundo ao tema da morte. Em português, ambos os sentidos estão contidos em "escatologia", donde a escolha de manter os termos em francês. (N.T.) 


\section{REFERÊNCIAS BIBLIOGRÁFICAS}

ALVAREZ LOBO, Ricardo. 1961. “Encuentro con los Amahuacas del Mapuya”. Misiones Dominicanas de/ Peru XLII(251): 16-23.

AMENYEDZI, Anani. 1984. Le rituel de la parole: la salutation gbedonaine et defofo chez les Eve du Togo. Thèse de 3ème Cycle. EHESS.

ARMENTIA, Fray Nicolas. 1976 [1882]. Diario de sus Viajes (1881-82). La Paz: Instituto Boliviano de Cultura.

BALZANO, Silvia. 1984. "Kako, a cultural hero of the Chacobos". Latin American Literature VIII (1): 26-34.

BARBOSA, S. M. 1986. Kancaia (ao povo Kaxarari). Porto Velho: CIMI.

BARBOSA, Theotonio. 1749. Informação da aldeia dos Abacaxi (e rio Madeira), que manda o P. Missionário Theotonio Barbosa ao P. Provincial, anno de 1749. Cod. CXV/2-15, n4. Biblioteca Pública de Evora.

BARRIENTOS, Bartolomé. 1902 [1568]. “Vida y hechos de Pero Menendez de Auiles, cauellero de la hordem de Sanctiago, Adelantado de la Florida: do largamento se tratan las conquistas y poblaciones de la provincia de la Florida". In G. Garcia (ed.) Dos antiguas relaciones de la Florida. México: J. Aguilar Vera y Comp. pp.1-152.

BETENDORF, João F. 1910. “Chronica da missão dos padres da Companhia de Jesus". Revista do Instituto Histórico e Geográfico Brasileiro 72.

CARID NAVEIRA, Miguel Alfredo. 1999. Yawanawa: da guerra à festa. Dissertação de Mestrado. Florianópolis: Universidade Federal de Santa Catarina.

COLLETT, Peter. 1983. "Mossi salutations". Semiotica 45: 191-248.

CRÉPEAU, Robert. 1993. “La continuité du vécu et la capacité transformatrice du rite: un exemple amazonien”. Ethnographie 89(113): 79-96.

DEAN, Bartholomew. 1994. "Forbidden Fruit: Infidelity, Affinity and Bride service among the Urarina of Peruvian Amazonia". Journal of the Royal anthropological Institute 1: 87-110.

DENEVAN, William. 1980. La Geografia Cultural Aborigen de los Llanos de Mojos. La Paz: Juventud.

DIAZ DEL CASTILLO, Bernal. 1987 [1590]. Histoire Véridique de la conquête de la Nouvelle-Espagne. Paris: La Découverte.

DURANTI, Alessandro. 1992. "Language and Bodies in Social Space: Samoan Ceremonial Greetings". American Anthropologist 94(3): 657-691.

EAKIN, Lucille. 1991. “Lecciones para el aprendizaje del idioma yaminahua". Serie Lingüística Peruana, Documento de Trabajo N²2. Lima/Pucallpa: Ministerio de Educación/ILV.

EDER, Francisco J. SJ. 1985. Breve Descripcion de las Reducciones de Mojos ca. 1772. Cochabamba: Historia Boliviana.

ERIKSON, Philippe. 1988. "Apprivoisement et Habitat chez les Amérindiens Matis (Langue Pano, Amazonas, Brésil)". Anthropozoologica 9: 25-35.

1989. "Les Matis de la tête aux pieds et du nez aux fesses". In M-L. Beffa \& R. Hamayon (eds.) Les Figures du Corps. Nanterre: Publications du Laboratoire d'Ethnologie et de Sociologie Comparative de I'Université de Paris X-Nanterre. pp. 287-295.

1993. "A onomástica matis é amazônica?". In E. Viveiros de Castro \& M. Carneiro da Cunha (eds.) Amazônia: Etnologia e História indígena. São Paulo: NHII/USP/FAPESP. pp. 323-338.

1996. La Griffe des Aïeux. Marquage du corps et démarquages ethniques chez les Matis d'Amazonie. Louvain/ Paris: Peeters.

2000. "Dialogues à vif. Note sur les salutations en Amazonie". In Monod-Becquelin, Aurore \& Philippe Erikson (eds.) Les Rituels du Dialogue. Promenades ethnolinguistiques en terres amérindiennes. Nanterre: Société d'Ethnologie. pp. 113-136. 
FAUST, Norma. 1973. Lecciones para el aprendizaje del idioma Shipibo-Conibo. Documento de Trabajo №1. Pucallpa: ILV, Ministerio de Educación.

FEATHER, Conrad. 2010. Elastic selves and fluid cosmologies: Nahua resilience in a changing world. Ph. D. Dissertation. St. Andrews: University of St Andrews.

FIRTH, Raymond. 1970. «Postures and gestures of respect». In J. Pouillon \& P. Maranda (eds.) Echanges et Communications vol. I. The Hague: Mouton. pp.188-209.

FOCK, Niels. 1963. Waiwai: Religion and Society of an Amazonian Tribe. Ethnography Serie 8. Copenhagen: Danish National Museum.

GALVÃO, Eduardo. 1996. Diários de Campo entre os Tenetehara, Kaioá e índios do Xingú. Marco Antonio Gonçalves (ed.). Rio de Janeiro: Editora UFRJ/Museu do Indio/Funai.

GALVIS R., Hortensia. 1995. Somos Bari. Bogotá: Editorial Presencia Ltda.

GNERRE, Maurizio. 1987. “The decline of dialogue: Ceremonial and mythological discourse among the Shuar and Achuar. In Joel Sherzer \& Greg Urban (eds.) Native South American Discourse. Berlin: Mouton de Gruyter. pp.307-341.

GOGGIN, John \& William Sturtevant. 1964. "The Calusa: a stratified nonagricultural society (with notes on sibling marriage)". In Ward H. Goodenough (ed.) Explorations in Cultural Anthropology. Essays in Honor of George Peter Murdock. New York: McGraw-Hill Book Company.

GOODY, Esther. 1974. "'Greeting', 'Begging' and Presentation of Respect". In J.S. Fontaine (ed.) The Interpretation of Ritual. London: Tavistock. pp.39-72.

GOULARD, Jean-Pierre. 1998. Les genres du corps. Conceptions de la personne chez les Ticuna de la haute Amazonie. Thèse de doctorat. Paris: EHESS.

HALL, Peter M. \& HALL, Dee Ann Spencer. 1983. “The handshake as interaction”. Semiotica 45(3-4): 249-264.

HEATH, Edwin R. 1883. “Exploration of the River Beni in 1880-1". Proceedings of the Royal Geographical Society (London) V: 327-347.

HERIARTE, Maurízio. 1948. “Descrição do Estado do Maranhão, Pará, Corupa e rio das Amazonas”. In Varnhagen, Francisco A. (ed.) História Geral do Brasil, vol. III. São Paulo: Melhoramentos. pp. 171-190.

HOWARD, Katherine. 1993. "A farsa dos visitantes". In E. Viveiros de Castro \& M. Carneiro da Cunha (orgs.) Amazônia: etnologia e historia indígena. São Paulo: NHII/USP/FAPESP.

HUXLEY, Matthew \& Cornell Capa. 1964. Farewell to Eden. New York: Harper \& Row.

JOURNET, Nicolas. 1995. La Paix des Jardins. Structures sociales des Indiens curripaco du haut Rio Negro (Colombie). Paris: Institut d'Ethnologie, Musée de l'Homme.

KENSINGER, Kenneth. 1995. How Real People Ought to Live: The Cashinahua of Eastern Peru. Illinois: Waveland Press, Prospect Heights.

KNEELAND, Harriet. 1979. Lecciones para el aprendizaje del idioma Mayoruna. Documento de Trabajo №14. Pucallapa: ILV/Ministerio de Educación.

KROEMER, Gunter. 1985. Cuxiurara. O Purus dos Indígenas, ensaio etno-histórico e etnográfico sobre os índios do médio Purus. São Paulo: Edições Loyola.

LABATUT, R. 1989. “De la salutation peule". In G. Calame Griaule Graines de Parole: puissance du verbe et traditions orales. Paris: CNRS. pp. 65-77.

LIMA, Edilene C. 1997. “A onomástica katukina é pano?". Revista de Antropologia 39(2): pp. 7-30.

LIZOT, Jacques. 1994. “Words in the Night: The Ceremonial Dialogue - One expression of Peaceful Relationships Among the Yanomami". In Sponsel, Leslie \& Thomas Gregor (eds.) The Anthropology of Peace and Nonviolence. London: Lynne Rienner Publishers. pp.213-240. 
MARTINEZ, Rosalia. 1992. “Boire pour jouer, jouer pour boire. Relations entre musique et alcool dans la fiesta des Jalq'a (Bolivie)". Cahiers de Sociologie Economique et culturelle, ethnopsychologie 18: 63-78.

MCCALLUM, Cecilia. 1989. Gender, Personhood and Social Organization Amongst the Cashinahua of Western Amazonia. Ph. D. Dissertation. London School of Economics.

1996. “The Body That Knows: From Cashinahua Epistemology to a Medical Anthropology of Lowland South America". Medical Anthropology Quarterly 10(3): 342-372.

MENÉNDEZ, Miguel. 1984/5. "Contribuição ao estudo das relações tribais na área Tapajós-Madeira”. Revista de Antropologia 27/28: 271-286.

MÉTRAUX, Alfred. 1962. Les Incas. Le Seuil: Paris.

MITRANI, Philippe. 1978. "Salud y Enfermedad en la Concepción Yaruro (Ensayo de Antropología Médica)". Montalban 8: 329-390.

MONTAGNER MELATTI, Delvair. 1985. O mundo dos espíritos: estudo etnográfico dos ritos de cura Marubo. Tese de doutorado. Brasília: UnB.

NADEN, Tony. 1980. "How to Greet in Bisa". Journal of Pragmatics 4: 137-145.

NORDENSKIÖLD, Erland. 1924. The Ethnography of South America as seen from Mojos in Bolivia. Comparative Ethnographical Studies 3. Göteborg: Göteborgs Etnografiska Museum.

PASSES, Alan, 2004. "The Place of Politics: Powerful Speech and Women Speakers in Everyday Pa'ikwene (Palikur) Life". The Journal of the Royal Anthropological Institute 10 (1): 1-18.

PERRIN, Michel. 1992. Les Praticiens du rêve, un exemple de chamanisme. Paris: PUF.

RIVIÈRE, Peter. 1971. "The Political Structure of the Trio Indians as Manifested in a System of Ceremonial Dialogue". In T.O. Beidelman (ed.) The Translation of Culture. London: Tavistock Publications. pp. 293-311.

SAIGNES, Thierry (ed.). 1993. Borrachera y memoria. La experiencia de lo sagrado en los Andes. La Paz: Hisbol/IFEA. SCHIFFRIN, Deborah. 1974. "Handwork as Ceremony: The Case of the Handshake". Semiotica 12: 189-202.

SCHOEPF, Daniel. 1979. La marmite Wayana, cuisine et société d'une tribu d'Amazonie. Musée d'Ethnographie de Genève. . 1998. "Le domaine des colibris: accueil et hospitalité chez les Wayana". Journal de la Société des Américanistes 84(1): 99-120.

SCHOTTMAN, Wendy. 1995. "The Daily Ritual of Greeting among the Baatombu of Benin". Anthropological Linguistics 37(4): 487-523.

SURRALLÉS, Alexandre. 2003. "Face to Face: Meaning, Feeling and Perception in Amazonian Welcoming Ceremonies". The Journal of the Royal Anthropological Institute 9 (4): 775-791.

TASTEVIN, R. P. Constantin. 1909. “De la formule de Salutation chez les Indigènes du Brésil”. Anthropos IV: $139-141$. \& 14-35.

. 1925. "Le fleuve Muru. Ses habitants. Croyances et Moeurs Kachinaua". La Géographie XLIII \& XLIV: $403-422$

URBAN, Greg. 1986. "Ceremonial Dialogues in South America”. American Anthropologist 88(2): $371-386$.

VIERTLER, Renate. 1976. Greeting, hospitality and Naming among the Bororo of Central Brazil. Austin, TX: Southwest Ed. Development Lab.

WAGLEY, Charles. 1977. Welcome of Tears. The Tapirapé Indians of Central Brazil. NewYork: Oxford University Press.

WHITON, Luis, H. Bruce Green, \&Richard Momsen. 1964. “The Isconahua of the Remo". Journal de la Société des Américanistes LIII: 84-124.

WIERZBICKA, Anna. 1995. “Kisses, handshakes, bows: The semantics of nonverbal communication”. Semiotica 103(3-4): 207-252. 


\section{Diálogos à flor da pele... Nota sobre as saudações na Amazônia}

\section{RESUMO}

O tema das saudações não é inteiramente novo para a área amazônica. Entretanto, é preciso observar que são essencialmente as formas de saudação extraordinárias que têm retido a atenção dos americanistas. Sabemos muito mais sobre os sofisticados diálogos rituais praticados em encontros de caráter cerimonial que sobre as práticas cotidianas. Gostaria então de deter-me um pouco sobre a arte e a maneira de se saudar entre algumas etnias amazônicas (Matis e Chacobo, particularmente), o que não me impedirá de sucumbir ao costume de dizer algumas palavras sobre as saudações extraordinárias que anteriormente se praticavam no seio de uma entre elas, os Chacobo da Amazônia boliviana. A hipótese que proporei aqui é que a maior codificação das fórmulas de saudação chacobo, em comparação àquelas dos Matis, não é sem relação com suas diferenças no plano da organização social e política.

PALAVRAS-CHAVE: Saudações; diálogos cerimoniais; Chacobo; Matis.

\section{Dialogues à vif... Note sur les salutations en Amazonie}

\section{RESUMÉ}

Le thème des salutations n'est pas entièrement neuf pour l'aire amazonienne. Cependant, force est de constater que ce sont essentiellement les formes de salutation extra-ordinaires qui ont retenu l'attention des américanistes. On en sait beaucoup plus sur les dialogues rituels sophistiqués pratiqués à l'occasion de rencontres à caractère cérémoniel, que sur les pratiques quotidiennes. Je voudrais donc m'attarder un peu sur l'art et la manière de se saluer dans quelques ethnies amazoniennes (Matis et Chacobo, particulièrement), ce qui ne m'empêchera pas de sacrifier à la coutume en disant quelques mots des salutations extra-ordinaires qui se pratiquaient antérieurement au sein de l'une d'entre elles, les Chacobo d'Amazonie bolivienne. L'hypothèse que j'irai proposer ici est que la plus grande codification des formules de salutation chacobo par rapport à celles des Matis n'est pas sans rapport avec leurs différences sur le plan de l'organisation sociale et politique.

MOTS-CLÉS: Salutations; dialogues cérémoniels; Chacobo; Matis.

\section{Dialogues à vif... Remarks about the greetings in the Amazon}

\section{ABSTRACT}

The analyses of greetings is not new for the Amazon region. However, it is the extraordinary ways of greeting that have received special attention from the americanists. We know much more about the sophisticated ritual dialogues carried out in ceremonial meetings than about the daily practices. I intend to approach the art and the way of greeting in some ethnic groups of the Amazon (particularly Matis and Chacobo), as well as to provide some information about the extraordinary greetings that the Chacobo, from the Bolivian Amazon forest, used to practice. I propose the hypothesis that the greater codifying of the Chacobo greeting formulas, when compared to those used by the Matis, has to do with social and political differences between these two ethnic groups.

KEY WORDS: Greetings; cerimonial dialogues; Chacobo; Matis. 